\title{
FEEDBACK MECHANISM AMONG DECADAL OSCILLATIONS IN NORTHERN HEMISPHERE ATMOSPHERIC CIRCULATION, SEA ICE, AND OCEAN CIRCULATION
}

\author{
by \\ M. Ikeda \\ (Physical and Chemical Sciences, Department of Fisheries and Oceans, Bedford Institute of \\ Oceanography, Dartmouth, Nova Scotia B2Y 4A2, Canada)
}

\section{ABSTRACT}

Decadal oscillations of the ice cover in the Barents Sea are examined for the period since 1950. They are highly correlated with atmospheric circulation when that circulation has an anomalous low pressure over the Barents Sea and Eurasian Basin, while the ice cover is weakly correlated with local air temperature. A feedback mechanism between Barents Sea ice and the atmospheric circulation is suggested; increased cyclonic wind-stress curl reduces cold Arctic flow to the Barents Sea and reduces the sea ice. The reduced ice cover encourages heat flux from the Barents Sea to the atmosphere, tending to reinforce the low pressure. This positive feedback amplifies the oscillations of the air-iceocean system driven by external forcing with relatively weak decadal variability. A two-level ocean model, which is driven by prescribed buoyancy flux and wind stresses, confirms that Arctic outflow to the Barents Sea decreases during a cyclonic wind stress.

\section{INTRODUCTION}

Stewart (1978) and Baker (1986) suggested that climate change in the northern hemisphere may be related to sea ice and ocean circulation in the Arctic; i.e., there is feedback between the atmosphere and sea ice/ocean. In this paper, decadal time-scale variations, which have been observed to exist and may significantly influence human life, are studied.

Ikeda (in press) reconsidered correlations among decadal oscillations of northern $\mathrm{Hhmisphere}$ atmospheric circulation, ice cover and ocean circulation. Decadal oscillations of the ice cover are observed in the Barents Sea and Labrador Shelf, and are out of phase between these two regions. Heavy or light ice cover in these regions may be attributed to atmospheric conditions; when a low (high) anomaly exists over the Eurasian Basin, Europe is warm (cold) and Labrador is cold (warm) (van Loon and Rogers, 1978). Sea surface temperatures in the Barents Sea and Labrador Shelf also follow this seesaw pattern. Hence, ice cover anomalies in the Barents Sea and Labrador Shelf could be attributed to atmospheric pressure anomalies over the Eurasian Basin.

The question raised in this paper is whether there is feedback by which the sea ice and the ocean affect the atmosphere. In the ocean-ice-air feedback process, air temperature and atmospheric circulation may be modified by the degree of sea-ice coverage, which reflects solar radiation efficiently and reduces the heat flux from the ocean to the atmosphere at high latitudes by insulation. Ocean circulation and sea-ice distribution are in turn affected by wind stress and air temperature. A crucial area for the ocean-ice-air feedback may be the Barents Sea, which is the northernmost ice-free area.

In this paper, historical data are presented and an hypothesis of air-ice-ocean interactions is proposed. A twolevel Arctic Ocean model is used to examine oceanic response to variable wind stress.

\section{HISTORICAL DATA}

Historical data have been discussed thoroughly by Ikeda (in press) and only a summary is presented here. Monthly anomalies of areal sea-ice extent in the Barents Sea are taken from Mysak and Manak (1989) and plotted in Figure la. The anomalies, which are smoothed by a 25-month running mean, exhibit decadal oscillations. Annual air temperatures for the Barents Sea, taken from Kelly and others (1982), are shown in Figure 1b. The Barents Sea experienced a temperature minimum around 1968, reflecting the dominant cooling trend in the entire Arctic. No decadal oscillation is observed before 1965 .

The mean atmospheric circulation in the northern hemisphere can be represented by a westerly jet at midlatitudes. To examine variations, atmospheric pressure at the sea surface has been analyzed by Trenberth and Paolino (1981). The first EOF of the annual mean pressure field has a dominant low anomaly over the Eurasian Basin and two minor high anomalies over the Pacific and Europe. The smoothed time series in Figure 1c exhibits decadal oscillations, with positive (negative) values corresponding to $0.5-1.5 \mathrm{mbar}$ low (high) anomalies in the Eurasian Basin. In the period of the positive values, the meridional component of the mid-latitude jet contributes to northwesterly winds over Labrador and southwesterly winds in the Greenland Sea, as well as cyclonic wind-stress curl in the Barents Sea.

Monthly mean 700 mbar heights have been analyzed by Barnston and Livezey (1987). The time series are shown in Figure 1d for the first monthly EOFs in the three winter months (December-February), which are similar to the first annual EOF of the sea surface pressure. The interannual variations are similar to those of the annual EOF after 1965 , whereas no decadal oscillation is visible before 1965 in the winter EOF. Ikeda (in press) has found that the time series are insensitive to heights at which the data were collected.

There is an inverse correlation between the Barents Sea ice and air temperature after 1966, whereas ice variability before 1966 is not explained by air temperature. The air temperature is more highly correlated with the winter EOF of the atmospheric pressure (correlation coefficient $r$ of $0.75)$ than with the annual EOF $(r=0.45)$. Thus, air temperatures over the Barents Sea are dominated by winter temperatures, which are determined by the winter atmospheric circulation. Barents Sea ice is more highly correlated with the annual mean atmospheric circulation $(r=$ $0.79)$ than Barents Sea air temperature $(r=-0.52)$ and the winter circulation $(r=-0.66)$. These correlations suggest that the dynamic mechanisms that drive the ocean with a long time-scale are more important for Barents Sea ice than thermodynamic mechanisms affecting sea ice in any one season.

Water temperature anomalies in the Kola section $\left(33.5^{\circ} \mathrm{E}\right)$ in the Barents Sea have been re-analyzed by Leong (1988). The time series of the water temperature in Figure le is highly correlated with the air temperature $(r=0.77)$. 

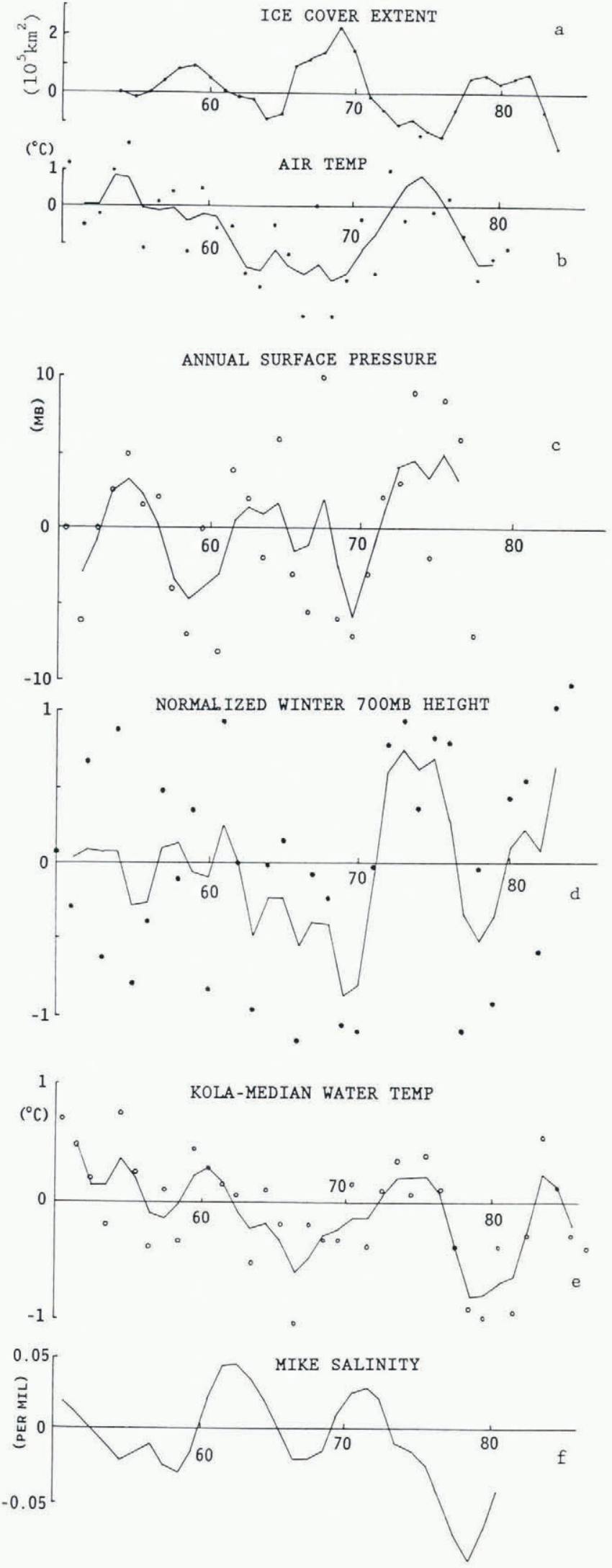

Fig. 1. (a) Monthly anomalies of areal sea-ice extent in the Barents Sea; (b) annual air temperature in the Barents Sea $\left(70-85^{\circ} \mathrm{N}, 20-50^{\circ} \mathrm{E}\right)$, where the original values are shown by solid circles, and lines show the values smoothed by the Hanning ( 3 year) filter; (c) the coefficient time series (open circles) of the first EOF of atmospheric pressure at sea-level along with the 3 year filtered time series; (d) the normalized time series of the first EOF of winter mean 700 mbar heights (solid circles); (e) water temperature anomalies at $0-200 \mathrm{~m}$ in the Kola section; and (f) salinity anomalies at $300 \mathrm{~m}$, Station Mike $\left(66^{\circ} \mathrm{N}\right.$, $2^{\circ} \mathrm{E}$ ). On each of these plots the $\mathrm{x}$-axis is in years.
However, correlation between the water temperature and sea ice is low $(r=-0.40)$. This is further evidence that Barents Sea ice is controlled more by a dynamic mechanism than by a thermodynamic mechanism. The salinity at a $300 \mathrm{~m}$ depth from Station Mike $\left(66^{\circ} \mathrm{N}, 2^{\circ} \mathrm{E}\right)$ plotted in Figure if represents upper layer properties and shows decadal oscillations. By comparison with the annual pressure field, the salinity decreased while a low pressure anomaly over the Eurasian Basin was strong. In the time series, the salinity variations seem to have a phase lag of 3 years with atmospheric circulation.

The above analyses lead to the following hypothetical link between the sea ice and atmospheric circulation. The low-pressure anomaly in the Eurasian Basin tends to produce cyclonic wind-stress curl over the Barents Sea and Fram Strait area. Cyclonic ocean circulation generated by the wind-stress curl acts to replace cold Arctic water (including sea ice) by warm Atlantic water, reducing Barents Sea ice. Thus, low-pressure anomalies in the Arctic tend to reduce Barents Sea ice. The quantitative discussion given below shows that the observed wind-stress variations can produce the observed variations in ice cover. The correlation coefficients obtained above are sensitive to the sea-ice data in the 1950s, when the data had lower quality (Walsh and Johnson, 1979). It should be mentioned that the importance of atmospheric circulation suggested here could be misleading.

A feedback mechanism from ice/ocean to atmospheric circulation is discussed next by referring to model studies. The general circulation model developed by the Canadian Climate Centre was run with two different ice covers (average and heavy), producing sea-level pressure higher on the extra ice-covered area by $\sim 4 \mathrm{mbar}$ (personal communication from Boer). As estimated using a linear wave model of Egger (1977), an extra ice-free area of $2 \times 10^{5} \mathrm{~km}^{2}$ in the Barents Sea for 3 months produces a low pressure anomaly of $3 \mathrm{mbar}$ in winter or $1 \mathrm{mbar}$ in the annual mean.

It is well known that the number of sunspots has a quasi-decadal oscillation. The number is highly correlated with the winter atmospheric circulation in the northern hemisphere (van Loon and Labitzke, 1988). However, it is doubtful that this weak variation in solar activity can cause the atmospheric circulation anomalies by itself (Kerr, 1982) A possible mechanism to enhance the weak variation is positive feedback, by which responses of the atmosphereocean system are amplified, between the atmosphere and ocean.

\section{DYNAMIC OCEAN MODEL}

In this section, an oscillatory response of the ocean to a wind stress is examined using a dynamic ocean model The two-level model used in this paper is similar to that in Ikeda (1987). The model has a rigid lid and a frictionless bottom. Hydrostatic and Boussinesq approximation are used, and non-linear advection terms are omitted in the momentum equations. The velocity field can be divided into barotropic and baroclinic components. Acceleration and horizontal viscous terms are retained in the barotropic momentum equations. The wind stress is assumed to determine Ekman transport, which drives the barotropic component, in addition to bottom topographic effects with feedback from the baroclinic component. The hydrostatic approximation relates the pressure to the vertically integrated density, which determines the baroclinic component under a geostrophic assumption.

As shown in Figure 2, a simple model domain is used in this paper, including the Canadian Basin, Eurasian Basin, Barents Sea, and Greenland Sea. The southwestern boundary of the Greenland Sea is a closed boundary in the model. The upper level is $300 \mathrm{~m}$ thick, and the total depth is $3000 \mathrm{~m}$ except for the Lomonosov Ridge $(1500 \mathrm{~m})$, Fram Strait $(2000 \mathrm{~m})$, the Eurasian Basin (linear slope from $3000 \mathrm{~m}$ at the Barents Sea side to $4000 \mathrm{~m}$ at Lomonosov Ridge), and Barents Sea $(300 \mathrm{~m})$.

The density equations have non-linear advection terms, and horizontal and vertical diffusion terms. To simulate buoyancy-driven circulation in the Arctic-Atlantic, buoyancy and density (negative buoyancy) are given in the Canadian 


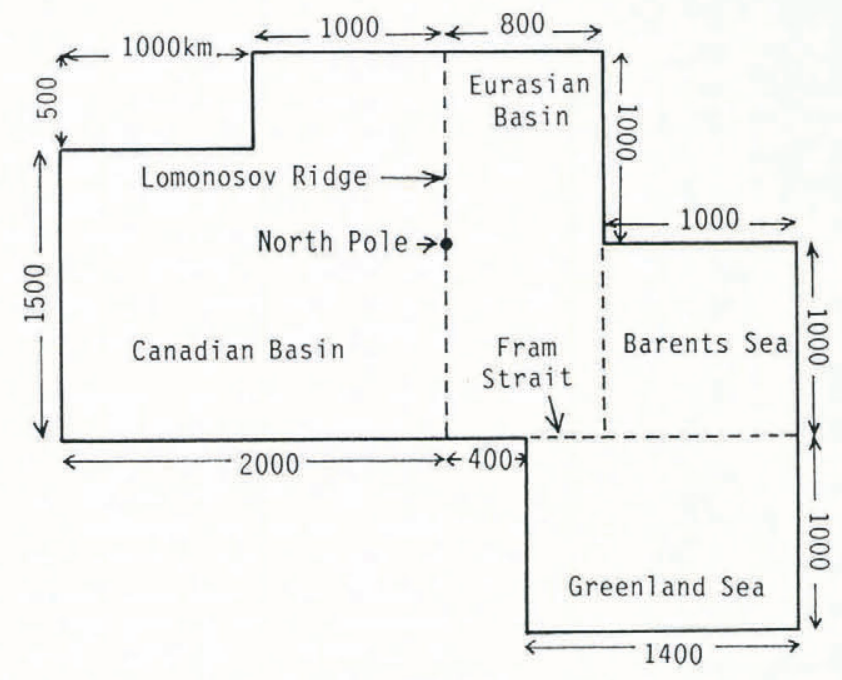

Fig. 2. The ocean-model domain used in this paper.

Basin and Greenland Sea, repectively. With this forcing, the Arctic water circulates clockwise in the upper level of the Canadian Basin and flows out via the Eurasian Basin to the Atlantic through Fram Strait. The Atlantic water enters the Arctic in the lower level as well as through the Barents

$$
\text { (a) } t=27 \mathrm{yr}
$$
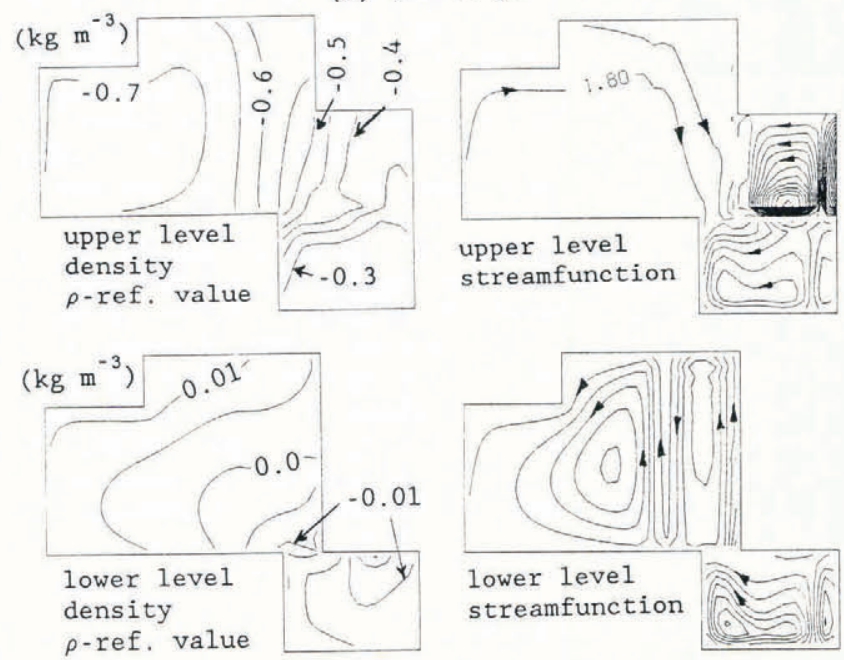

(b) $t=33 \mathrm{yr}$
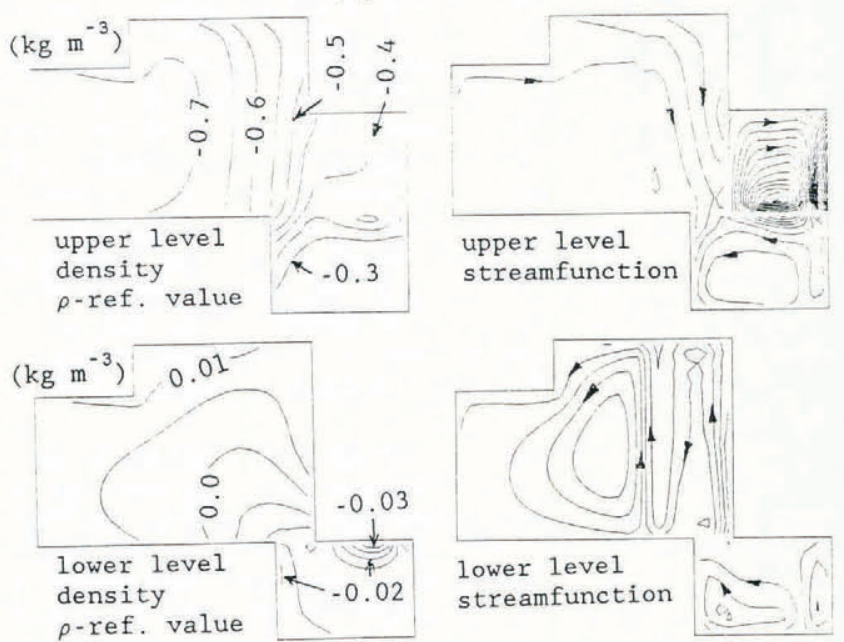

Fig. 3. The upper level density, lower level density, upper level stream function and lower level stream function at (a) $t=27$ years, and (b) $t=33$ years, for the 12 year period case. The contour intervals of the stream functions are $0.2 \times 10^{6} \mathrm{~m}^{3} \mathrm{~s}^{-1}$ everywhere, except for the Greenland Sea, where they are $10^{6} \mathrm{~m}^{3} \mathrm{~s}^{-1}$.
Sea. The horizontal viscosity and diffusion coefficients are $10^{3} \mathrm{~m}^{2} \mathrm{~s}^{-1}$, and a vertical diffusion coefficient is $10^{-4} \mathrm{~m}^{2} \mathrm{~s}^{-1}$. The numerical grid size is $100 \mathrm{~km}$ by $100 \mathrm{~km}$.

The initial density difference between the two levels is $0.5 \mathrm{~kg} \mathrm{~m}^{-3}$ in the Eurasian Basin. The initial density structure in the upper level is uniformly low (by -0.25) in the Canadian Basin and high (by 0.25) in the Greenland Sea. Although an equilibrium state is independent of the initial structure in the upper level, the solution converges faster with this initial condition than it does with a uniform upper level.

In addition to a steady wind-stress curl of $3 \times 10^{-8} \mathrm{Nm}^{2}$ over the Greenland Sea, an oscillatory wind-stress curl, with an amplitude of $10^{-8} \mathrm{~N} \mathrm{~m}^{-2}$, is applied over the Eurasian Basin, Barents Sea and Greenland Sea. The wind stress oscillates to be cyclonic in the first half period and anticyclonic in the second half. For a 12 -year period, calculations are carried out for 36 years. For the third period (24-36 years), density structures, and stream-functions are shown in Figure 3 for the cyclonic (27 years) and anticyclonic ( 33 years) maximum wind stresses. The evolution of the solution is shown in Figure 4.

The solution tends to converge to an equilibrium state. As shown by the stream-function at the northwestern corner of the Barents Sea, Arctic outflow to the Barents Sea is reduced during the cyclonic period (Fig. 4a). This weaker Arctic outflow is exhibited also by the weaker upper level flow in the Eurasian Basin during the cyclonic period (Fig. 3). The variability of this flow is well related to the zonal density gradient in the lower level, which supports the southward upper level flow at the Barents Sea-Eurasian Basin boundary.

During the cyclonic period, the Barents Sea becomes denser by receiving more (warmer) Atlantic Water in the Greenland Sea. Here the higher density in the Barents Sea is interpreted as representing less ice. Thus, a cyclonic wind stress tends to reduce Barents Sea ice. The area with $\rho<\rho_{0}-0.35 \mathrm{~kg} \mathrm{~m}^{-3}$ in the Barents Sea, less by $2 \times 10^{5} \mathrm{~km}^{2}$ in the cyclonic period (Fig. 3), is comparable with the observed ice-cover variability (Fig. 1). The density variations have maxima and minima about 2 years later than the maximum and minimum of wind-stress curl.

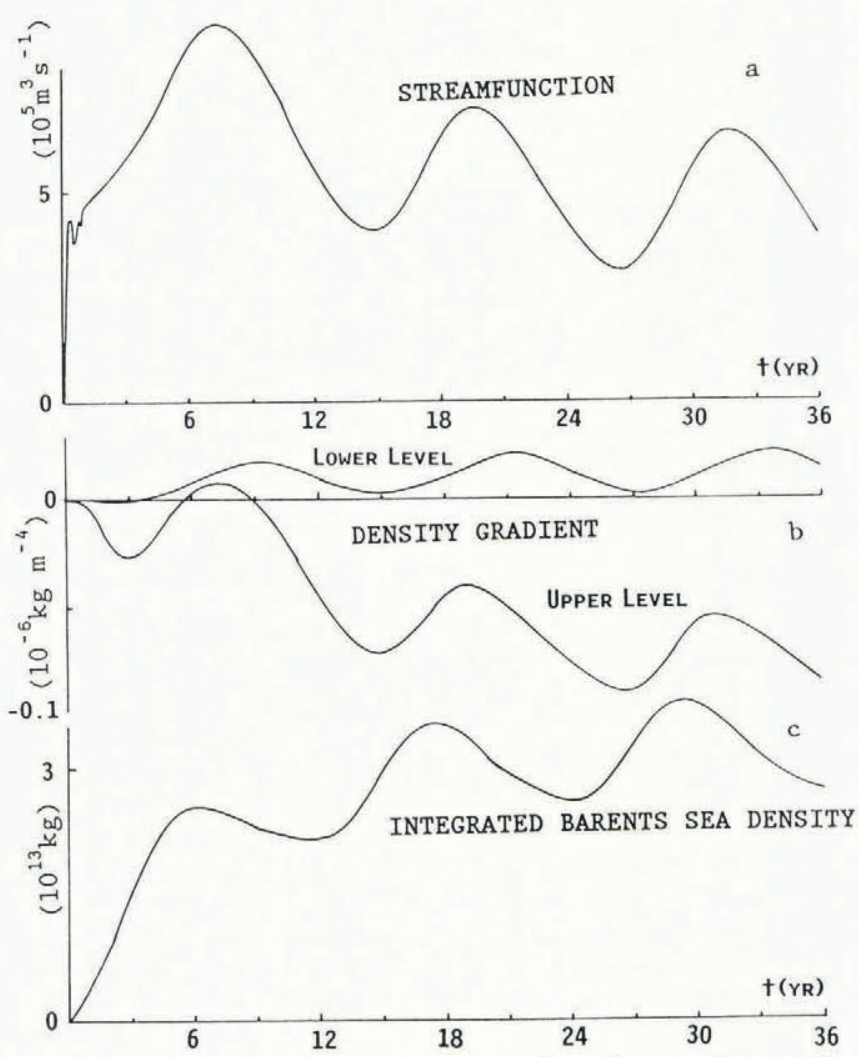

Fig. 4. The evolution of (a) stream function at the northwestern corner of the Barents Sea, showing the Arctic outflow to the Barents Sea; (b) the meridional density gradients in the upper and lower levels at the Eurasian Basin-Barents Sea boundary; and (c) density gain in the Barents Sea. 


\section{DISCUSSION}

In the numerical calculation, the density variability in the Barents Sea has a 2 year delay to the wind stress, whereas there is no delay in the observations. A response time-scale in the Barents Sea depends on detailed flow field of the Arctic outflow; speed, width, vertical profile, and so on. The Barents Sea water is well mixed and gradually replaced by outside water in the present model. If the ice edge position in the Barents Sea responded more quickly to the Arctic outflow, the time lag would be reduced. Hence, baroclinicity, more detailed bottom topography and presence of sea ice should be included in a more comprehensive model of the Barents Sea. In this paper, however, a general circulation pattern in the entire Arctic is examined to show responses of Arctic outflow to the Barents Sea.

Coupling of a sea-ice model with the ocean model, inclusion of thermodynamics, more realistic geometry and consideration of the atmospheric responses to oceanic conditions will be included in future work.

\section{ACKNOWLEDGEMENTS}

The work in this paper was supported by the Federal Panel on Energy Research and Development.

\section{REFERENCES}

Baker, D.J. 1986. The Arctic's role in climate. Oceanus, 29(1), 41-46.

Barnston, A.G. and R.E. Livezey. 1987. Classification, seasonality and persistence of low-frequency atmospheric circulation patterns. Mon. Weather Rev., 115, 1083-1126.

Egger, J. 1977. On the linear theory of the atmospheric response to sea surface temperature anomalies. J. Atmos. Sci., 34, 603-614.
Ikeda, M. 1987. Wind effects on the buoyancy-driven general circulation in a closed basin using a two-level model. J. Phys. Oceanogr., 17, 1707-1723.

Ikeda, M. In press. Decadal oscillations of the air-ice-ocean system in the Northern Hemisphere. Atmosphere-Ocean, 28, 106-139.

Kelly, P.M., P.D. Jones, C.B. Sear, B.S.G. Cherry, and R.K. Tavakol. 1982. Variations in surface air temperatures. Part 2. Arctic regions, 1881-1980. Mon. Weather Rev., 110, 71-83.

Kerr, R.A. 1982. Sun, weather, and climate: a connection? Science, 217, 917-919.

Loeng, $H$. 1988. The influence of climate on biological conditions in the Barents Sea. Dartmouth, Canada, Northwest Atlantic Fisheries Organization. (SCR Document 88/83.)

Mysak, L.A. and D.K. Manak. 1989. Arctic sea ice extent and anomalies, 1953-1984. Atmosphere-Ocean, 27, 376405 .

Stewart, R.W. 1978. The role of sea ice in climate. Oceanus, 21(4), 47-57.

Trenberth, K.V. and D.A. Paolino. 1981. Characteristic patterns of variability of sea level pressure in the Northern Hemisphere. Mon. Weather Rev., 109, $1169-1189$.

Van Loon, H. and K. Labitzke. 1988. Association between the 11-year solar cycle, the QBO, and the atmosphere. Part II. Surface and $700 \mathrm{mb}$ in the northern hemisphere in winter. J. Climatol., 1, 905-920.

Van Loon, H. and J.C. Rogers. 1978. The seesaw in winter temperatures between Greenland and northern Europe. Part I. General description. Mon. Weather Rev., 106, 296-310

Walsh, J.E. and C.M. Johnson. 1979. An analysis of Arctic sea ice fluctuations, 1953-77. J. Phys. Oceanogr., 9(3), 580-591. 